\title{
A 47-year-old stem cell transplant recipient with fever, cough and chest pain
}

\author{
Omar S Salh MD ${ }^{1}$, Omar N Nadhem MD¹, Sanket R Thakore MD¹, \\ Ruba A Halloush MD², Faisal A Khasawneh MD $^{3}$
}

OS Salh, ON Nadhem, SR Thakore, RA Halloush, FA Khasawneh. A 47-year-old stem cell transplant recipient with fever, cough and chest pain. Can Respir J 2015;22(3):144-146.

Infections and malignancies are among the most serious complications that follow organ or stem cell transplantation. They may have a mild course, and nonspecific and overlapping manifestations. The present article describes a case of symptomatic nodular pulmonary disease that complicated hematopoietic stem cell transplantation. It was diagnosed to be post-transplant lymphoproliferative disorder, a potential sequela of immunosuppression and a very difficult entity to treat in profoundly immunosuppressed patients.

Key Words: EBV; Post-transplant lymphoproliferative disorders

\section{Un greffé de cellules souches de 47 ans souffrant de fièvre, de toux et de douleur thoracique}

Les infections et les cancers font partie des pires complications qui suivent une transplantation d'organe ou une greffe de cellules souches. Ces maladies peuvent s'associer à une évolution bénigne et à des manifestations non spécifiques et communes. Le présent article décrit un cas de nodules pulmonaires symptomatiques qui a compliqué une greffe de cellules souches hématopoïétiques. Les médecins ont diagnostiqué un trouble lymphoprolifératif post-transplantation, une séquelle potentielle de l'immunosuppression et une entité très difficile à traiter chez les patients extrêmement immunodéprimés.

\author{
Learning objectives \\ - To underscore potential pulmonary complications following \\ stem cell transplantation. \\ - To review post-transplant lymphoproliferative disorders (PTLDs). \\ CanMEDS Competency: Medical Expert. \\ Pretest \\ - What are the risk factors for PTLDs? \\ - How would you treat PTLDs?
}

\section{CASE PRESENTATION}

A 47-year-old man, who was 274 days post matched unrelated peripheral blood stem cell transplant for chronic lymphocytic leukemia, was admitted on February 6 with fever, dry cough and left upper chest pain. The patient was hospitalized between January 24 and February 1 with fever and shortness of breath. He was diagnosed with pneumonia and treated with vancomycin and cefepime. Bronchoalveolar lavage (BAL) at the time was negative. The patient was discharged home on moxifloxacin. He returned one week later with persistent symptoms.

The patient had a history of graft-versus-host disease (GVHD) involving the skin, mouth and liver; a cytomegalovirus-positive donor; and $\mathrm{BK}$ viruria treated with a course of cidofovir. He drank alcohol socially but denied smoking or drug abuse.

His medications included methylprednisolone, tacrolimus, monthly nebulized pentamidine, valacyclovir, voriconazole, vancomycin and cefepime. He had no known drug allergies.

On examination, he was alert, oriented and in no acute distress. Vital signs were: temperature $102.1^{\circ} \mathrm{F}\left(38.9^{\circ} \mathrm{C}\right)$; heart rate 103 beats/min; blood pressure $95 / 57 \mathrm{mmHg}$; respiratory rate 20 breaths/min; and oxygen saturation $94 \%$ on $2 \mathrm{~L} / \mathrm{min}$ oxygen by nasal cannula. Significant physical examination findings included normal breath sounds with no crackles and no wheeze; normal heart sounds with no murmurs; soft abdomen with palpable nontender liver, no deep tenderness and positive bowel sounds; hyperpigmented macular skin rash of chronic

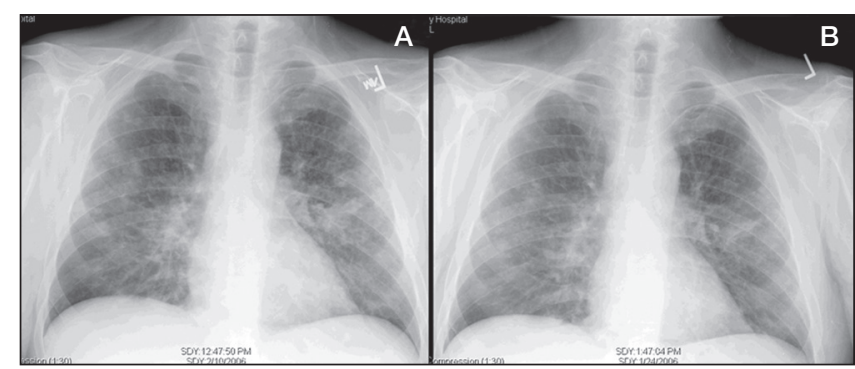

Figure 1) Chest $x$-rays from both admissions (January 24 [A] and February 6 [B]) revealing nonspecific bilaterial opacites

GVHD and no lower limb edema. The neurological examination was normal.

Laboratory findings included: white blood cell count $14.7 \times 10^{9} / \mathrm{L}$ (64\% neutrophils, $24 \%$ lymphocytes, $11 \%$ monocytes and $1 \%$ eosinophils); hemoglobin level $98 \mathrm{~g} / \mathrm{L}$; and platelet count $96 \times 10^{9} / \mathrm{L}$. Renal function and electrolyte findings included: creatinine $1.8 \mathrm{mg} / \mathrm{dL}$ (159.12 $\mu \mathrm{mol} / \mathrm{L})$; blood urea nitrogen $33 \mathrm{mg} / \mathrm{dL}$ (11.78 mmol/L); sodium $128 \mathrm{mEq} / \mathrm{L}$; potassium $5 \mathrm{mEq} / \mathrm{L}$; and carbon dioxide $18 \mathrm{mEq} / \mathrm{L}$. His liver function tests showed aspartate aminotransferase $19 \mathrm{IU} / \mathrm{L}$; alanine aminotransferase $25 \mathrm{IU} / \mathrm{L}$; alkaline phosphatase $434 \mathrm{IU} / \mathrm{L}$; and a total bilirubin level of $1.4 \mathrm{mg} / \mathrm{dl}(23.94 \mu \mathrm{mol} / \mathrm{L})$.

BAL cultures from the previous admission were negative for viruses, bacteria and fungi. Cytomegalovirus polymerase chain reaction testing in blood was negative. Serum and BAL galactomannen were negative. Serum cryptococcal antigen was negative. A chest $\mathrm{x}$-ray revealed nonspecific pulmonary opacities similar to the previous admission (Figure 1). Repeated computed tomography (CT) scan of the chest revealed disease progression (Figure 2).

Given the persisting nature of his complaints and the absence of a definitive infectious etiology, an open lung biopsy was performed (Figures 3 and 4). It revealed occasional large cells and binucleated Reed-Sternberg cells (Figure 3) that stained positive for CD30 and CD15, and were negative for CD45, CD20 and CD3 immunostains

${ }^{1}$ Department of Internal Medicine, Texas Tech University Health Sciences Center; ${ }^{2}$ Amarillo Pathology Group; ${ }^{3}$ Section of Pulmonary and Critical Care Medicine, Department of Internal Medicine, Texas Tech University Health Sciences Center, Amarillo, Texas, USA

Correspondence: Dr Faisal A Khasawneh, Texas Tech University Health Sciences Center, 1400 South Coulter Street, Amarillo, Texas 79106,

USA. Telephone 806-354-5480, fax 806-354-5765, e-mail faisal.khasawneh@ttuhsc.edu 


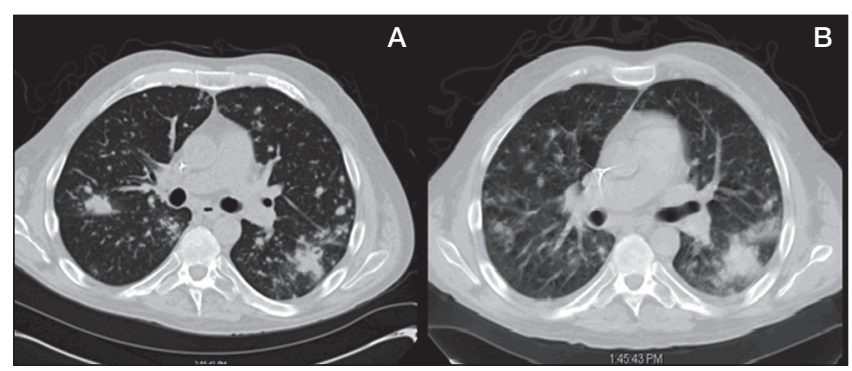

Figure 2) Computed tomography scans of chest from both admissions (January $24[\mathrm{~A}]$ and February $6[\mathrm{~B}]$ ) revealing nonspecific nodular opacities with evidence of progression and development of ground-glass opacities on the later scans. There was no lymphadenopathy or significant pleural effusion

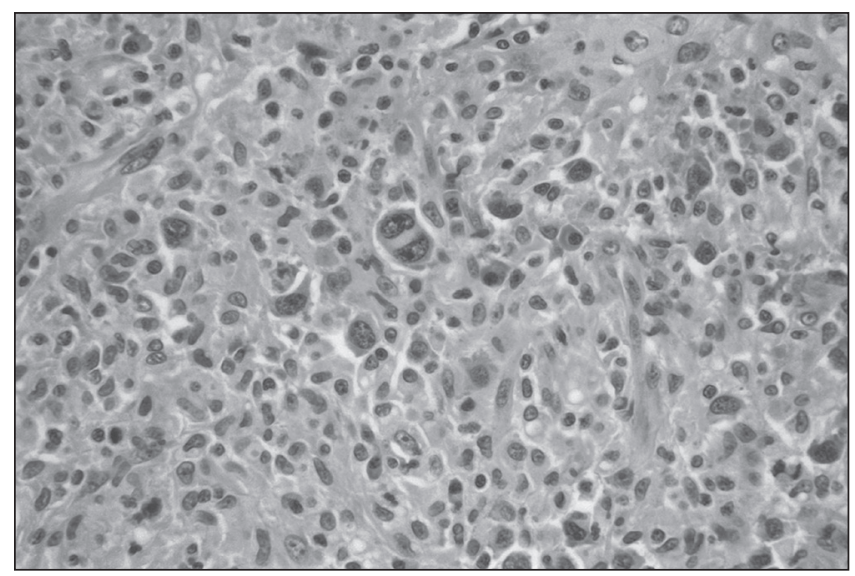

Figure 3) Lung biopsy revealing pulmonary infiltrate with occasional large cells and binucleated Reed-Sternberg cells (hematoxylin and eosin stain, original magnification $\times 400$ )

(Figure 4). Epstein-Barr virus (EBV) in situ hybridization was positive in the large cells (Figure 5), confirming EBV-related PTLD/Hodgkin lymphoma. He was started on chemotherapy with transient improvement in his symptoms. He was readmitted to hospital six weeks later with multilobar pneumonia but, unfortunately, succumbed to multiorgan failure.

\section{DISCUSSION}

PTLDs comprise a spectrum of lymphoid proliferation in the setting of immunosuppression that follows solid organ or hematopoietic stem cell transplantation (HSCT). It ranges from EBV-driven polyclonal proliferation to EBV-positive or, much less likely, EBV-negative lymphomas. PTLDs are classified into reactive plasmacytic hyperplasia or infectious mononucleosis-like PTLD; polymorphic PTLD; monomorphic lymphoma of B cell or, rarely, T cell lineage; or Hodgkin lymphoma, which is the least common of the four classes.

Several conditions can predispose to the development of PTLDs such as the transplanted organ, EBV serology of the donor and recipient, intensity of immunosuppression, and the incidence and frequency of rejection episodes (1). The incidence of PTLD in HSCT patients is approximately $1 \%$, and ranges between $1 \%$ and $5 \%$ in solid organ transplant recipients (2). Hodgkin lymphoma/PTLD in adults is exceedingly rare (3). It is more common in children, especially following solid organ transplantation. Its incidence in one series involving 273 patients was $1.8 \%$ (4) and, in a second series involving 170 patients (5), it was diagnosed in $3.4 \%$ of cases. Reported risk factors for PTLD after HSCT include T cell depletion of the donor marrow, antithymocyte globulin use, unrelated or human leukocyte antigen mismatched graft, acute and chronic GVHD, $\geq 50$ years of age at transplantation, and second transplantation (6). The risk for developing PTLD is highest in the first six months following transplantation, with $70 \%$ of cases

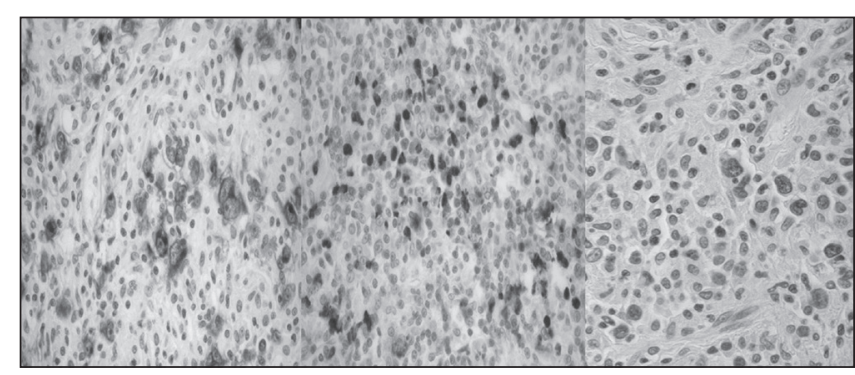

Figure 4) Immunohistochemical stains for CD30, CD15 and CD20 show the Reed-Sternberg cells to be positive for CD30 (left panel), CD15 (middle panel) and negative for CD20 (right panel) (original magnification $\times 400$ )

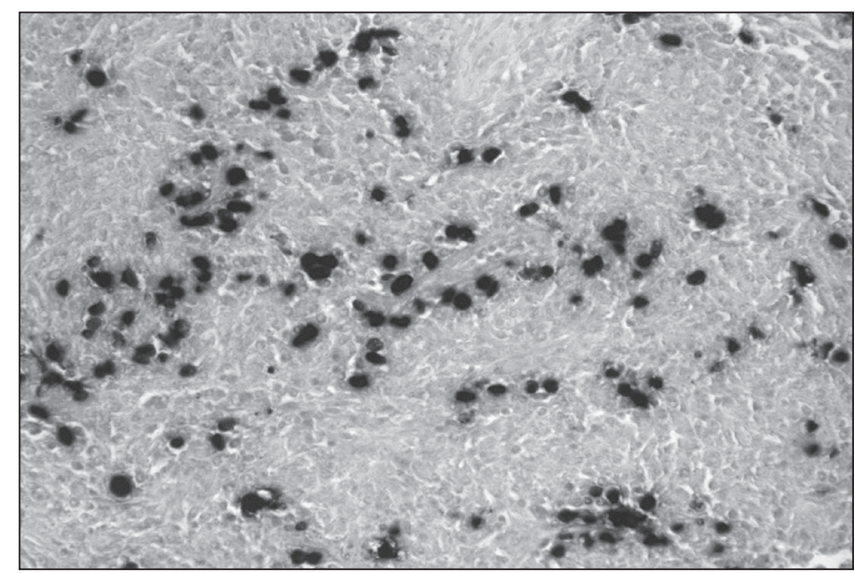

Figure 5) Epstein-Barr in situ hybridization is positive in the large cells (original magnification $\times 400$ )

reported during that time frame (7). Six months is the time it normally takes for immune reconstitution (7). The incidence of PTLD in solid organ transplants is highest in intestinal transplantation followed by combined heart-lung transplantation.

EBV reactivation of donor cells or of seropositive patients accounts for most cases of EBV-related PTLD. EBV-related PTLD is more likely to develop after allogeneic HSCT compared with autologous or cord blood HSCT (8). EBV-negative PTLDs account for $10 \%$ to $20 \%$ of PTLD cases (8).

The clinical presentation of PTLD is dependent on the extent of the disease. PTLD can be nodal or extranodal, and it can involve individual organ systems or be disseminated. Patients may report fever, lymphadenopathy and respiratory complaints, among others. PTLD tends to involve the transplanted organ in 30\% of cases and it commonly involves the gastrointestinal tract, liver, lungs and the central nervous system (1).

A case series described thoracic presentation of PTLD in 11 of $>4500$ solid organ and HSCT recipients (1). Fever was the most commonly reported symptom. Other complaints included pleuritic chest pain, anorexia and weight loss. The most common radiological findings in the above case series was isolated multiple discrete pulmonary nodules and mediastinal lymphadenopathy. Patchy airspace disease and pleural effusion have also been reported.

The definitive diagnosis of PTLD requires tissue biopsy. In situ hybridization or immunochemistry staining is needed to define EBV association. Identifying EBV DNA in peripheral blood monocytes may help to support the diagnosis.

Immunosuppression reduction, if feasible, can be the first step in treating PTLD that develops following solid organ transplantation. It is less effective in the treatment of PTLD that develops early after HSCT because of profound immunosuppression and the expected delay in immune reconstitution (8). The success rates of immunosuppression 
reduction alone have been overestimated in the past. A prospective trial that examined this approach reported an overall response rate of $6 \%(9)$. Patients in whom disease progresses despite the above require further therapy. Anti-CD20 monoclonal antibodies (eg, rituximab) can be effective, with an overall response rate of $55 \%$, but it may lead to further immunosuppression $(10,11)$. Factors predictive of a positive response to anti-B cell monoclonal antibodies include short interval between transplantation and PTLD onset, a small number of involved sites and the absence of central nervous system involvement (12). In contrast, poor response was reported in patients with elevated lactate dehydrogenase levels (11). Sequential therapy (four weeks of rituximab followed by four weeks of combination chemotherapy with cyclophosphamide, doxorubicin, vincristine and prednisone) was reported to be better than rituximab monotherapy plus chemotherapy at relapse (13). The median overall survival with sequential therapy was 6.6 years compared with 3.5 years with rituximab monotherapy. In most cases, PTLD results from the proliferation of latently EBV-infected B cells, which renders antiviral therapy ineffective. Adaptive transfer of EBV-specific cytotoxic T cell lines is effective (response rate 64\%); however, this therapy has limited availability $(14,15)$.

The mortality rate of PTLD is high, ranging between $60 \%$ and $80 \%$ (16). Disseminated disease and PTLD that develops in the setting of heart and lung transplantation carries a poor prognosis (1). The inability to reduce immunosuppression in the latter patient population may explain the poor outcome. Some transplant centres perform sequential quantitative EBV DNA nested polymerase chain reaction titres in blood. Pre-emptive therapy with rituximab is initiated if the titres show rising trends. Furthermore, there is a growing interest in EBVrelated PTLD prevention in high-risk HSCT patients. Combining low-dose rituximab during the conditioning regimen and using serolimus for GVHD prophylaxis may be helpful in that regard (8).

\section{Post-test \\ - What are the risk factors for PTLDs?}

Several conditions can predispose to the development of PTLD such as the transplanted organ, EBV serology of donor and recipient, intensity of immunosuppression, and the incidence and frequency of rejection episodes. Reported risk factors for PTLD after HSCT include T cell depletion of the donor marrow, antithymocyte globulin use, unrelated or human leukocyte antigen-mismatched graft, acute and chronic GVHD, $\geq 50$ years of age at transplantation, and second transplantation.

- How would you treat PTLDs?

Immunosuppression reduction, if feasible, can be the first step in treating PTLD. The success rates of immunosuppression reduction alone are rather poor. Patients in whom disease progresses despite the above require further therapy. Anti-CD20 monoclonal antibodies (rituximab) can be effective, with an overall response rate of $55 \%$ but it could lead to further immunosuppression. Chemotherapy is another option for treatment but carries a formidable risk of further immunosuppression. Sequential therapy (four weeks of rituximab followed by four weeks of combination chemotherapy with cyclophosphamide, doxorubicin, vincristine and prednisone), was reported to be better than rituximab monotherapy plus chemotherapy at relapse. The median overall survival with sequential therapy was 6.6 years compared with 3.5 years with rituximab monotherapy. Antiviral therapy is not effective. Although adaptive transfer of EBV-specific cytotoxic T cell lines may be effective, it has limited availability.
DISCLOSURES: The authors have no financial disclosures or conflicts of interest to declare.

\section{REFERENCES}

1. Halkos ME, Miller JI, Mann KP, Miller DL, Gal AA. Thoracic presentations of posttransplant lymphoproliferative disorders. Chest 2004;126:2013-20.

2. Semakula B, Rittenbach JV, Wang J. Hodgkin lymphoma-like posttransplantation lymphoproliferative disorder. Arch Pathol Lab Med 2006;130:558-60.

3. Okuno K, Horie Y, Kanai K, et al. Epstein-Barr virus associated post-transplant Hodgkin lymphoma in an adult patient after cord blood stem cell transplantation for acute lymphoblastic leukemia. J Clin Exp Hematop 2009;49:45-51.

4. Penn I. De novo malignances in pediatric organ transplant recipients. Pediatr Transplant 1998;2:56-63.

5. Ranganathan S, Webber S, Ahuja S, Jaffe R. Hodgkin-like posttransplant lymphoproliferative disorder in children: Does it differ from posttransplant Hodgkin lymphoma? Pediatr Dev Pathol 2004; 7:348-60

6. Landgren O, Gilbert ES, Rizzo JD, et al. Risk factors for lymphoproliferative disorders after allogeneic hematopoietic cell transplantation. Blood 2009;113:4992-5001.

7. Curtis RE, Travis LB, Rowlings PA, et al. Risk of lymphoproliferative disorders after bone marrow transplantation: A multi-institutional study. Blood 1999;94:2208-16.

8. Reddy N, Rezvani K, Barrett AJ, Savani BN. Strategies to prevent EBV reactivation and posttransplant lymphoproliferative disorders (PTLD) after allogeneic stem cell transplantation in high-risk patients. Biol Blood Marrow Transplant 2011;17:591-7.

9. Swinnen LJ, LeBlanc M, Grogan TM, et al. Prospective study of sequential reduction in immunosuppression, interferon alpha-2B, and chemotherapy for posttransplantation lymphoproliferative disorder. Transplantation 2008;86:215-22.

10. Oertel SH, Verschuuren E, Reinke P, et al. Effect of anti-CD 20 antibody rituximab in patients with post-transplant lymphoproliferative disorder (PTLD). Am J Transplant 2005;5:2901-6.

11. Choquet S, Leblond V, Herbrecht R, et al. Efficacy and safety of rituximab in B-cell post-transplantation lymphoproliferative disorders: Results of a prospective multicenter phase 2 study. Blood 2006;107:3053-7.

12. Benkerrou M, Jais JP, Leblond V, et al. Anti-B-cell monoclonal antibody treatment of severe posttransplant B-lymphoproliferative disorder: Prognostic factors and long-term outcome. Blood 1998;92:3137-47.

13. Trappe R, Oertel S, Leblond V, et al. Sequential treatment with rituximab followed by $\mathrm{CHOP}$ chemotherapy in adult B-cell posttransplant lymphoproliferative disorder (PTLD): The prospective international multicentre phase 2 PTLD-1 trial. Lancet Oncol 2012;13:196-206.

14. Haque T, Wilkie GM, Jones MM, et al. Allogeneic cytotoxic T-cell therapy for EBV-positive posttransplantation lymphoproliferative disease: Results of a phase 2 multicenter clinical trial. Blood 2007;110:1123-31.

15. Wagner HJ, Cheng YC, Huls MH, et al. Prompt versus preemptive intervention for EBV lymphoproliferative disease. Blood 2004;103:3979-81.

16. Ocheni S, Kroeger N, Zabelina T, et al. EBV reactivation and post transplant lymphoproliferative disorders following allogeneic SCT. Bone Marrow Transplant 2008;42:181-6. 


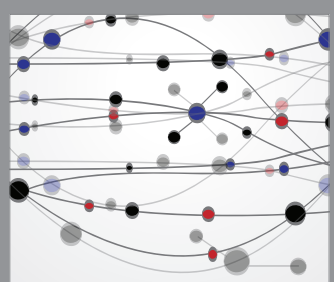

The Scientific World Journal
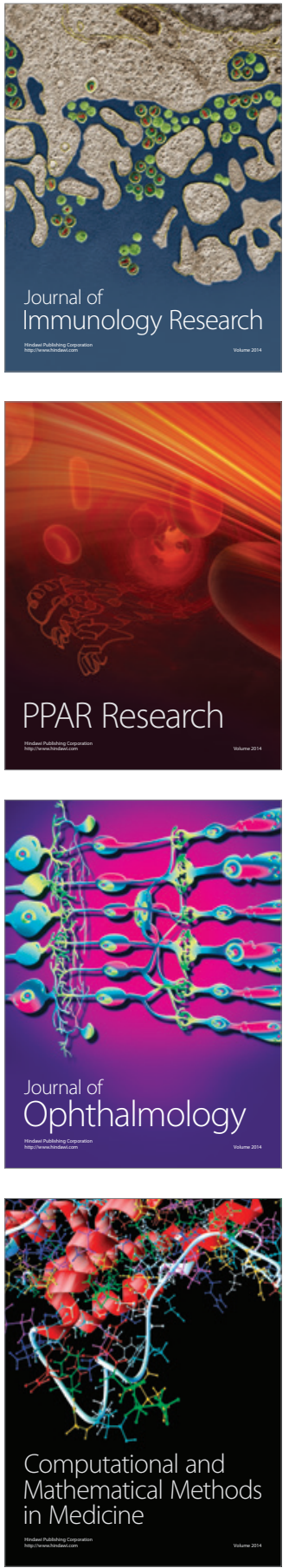

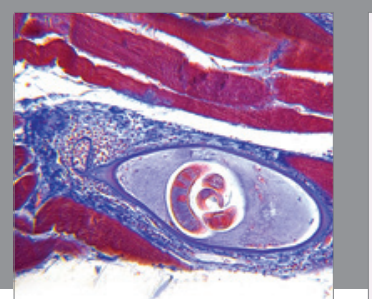

Gastroenterology Research and Practice

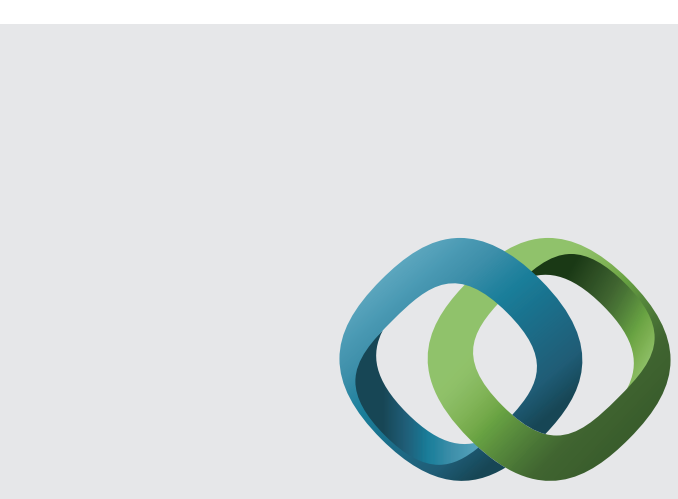

\section{Hindawi}

Submit your manuscripts at

http://www.hindawi.com
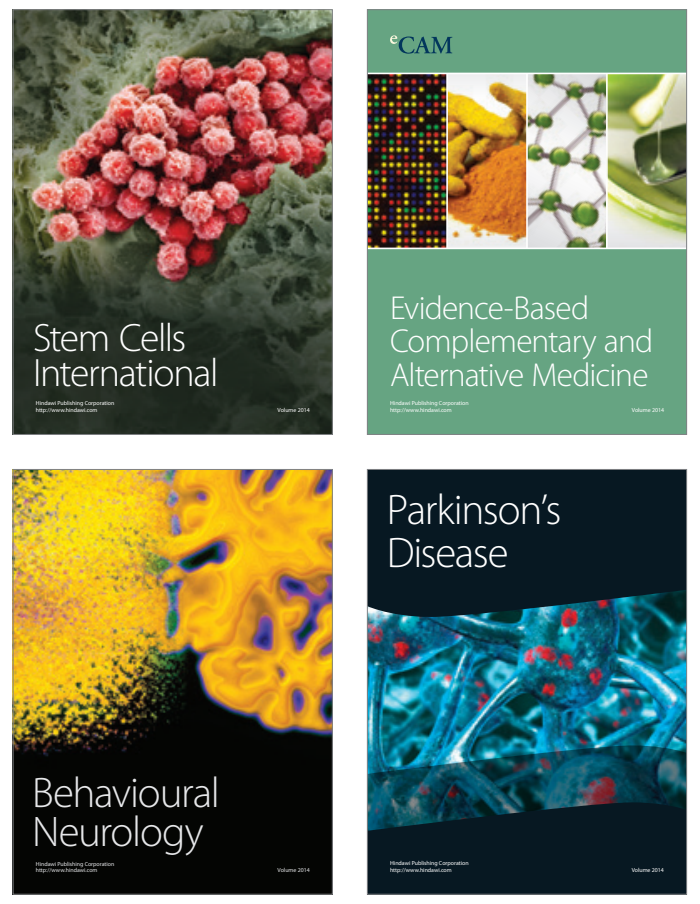
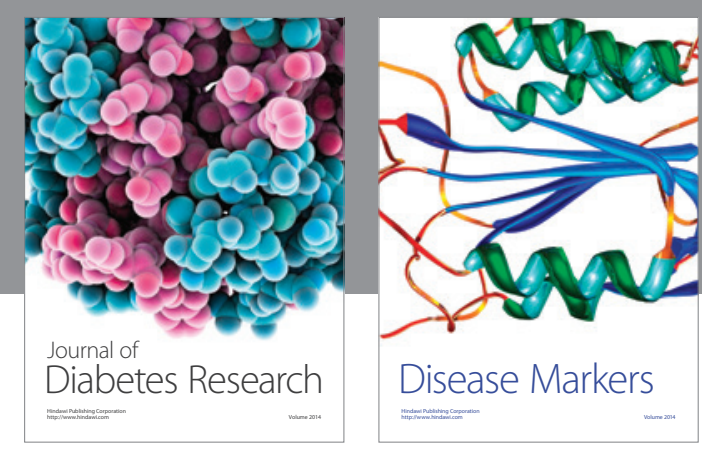

Disease Markers
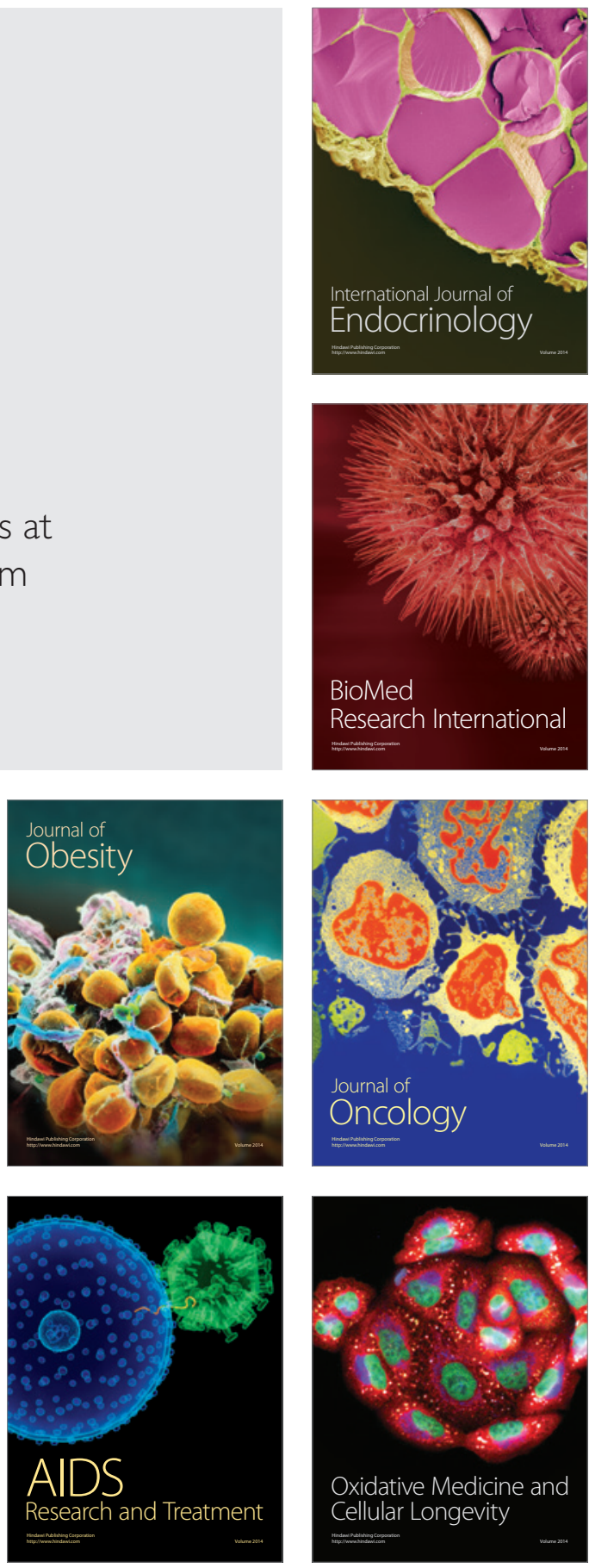